\title{
Sustainable and Renewable Energy Application: From Green Buildings to Green Sustainability
}

\author{
Te Fu Chen ${ }^{1, *}$, Tsai-fong $\operatorname{Tan}^{2}$ and Chieh-Heng $\mathrm{Ko}^{3}$ \\ ${ }^{1}$ Department of Business administration, Lunghwa University of Science and Technology, Taiwan \\ ${ }^{2}$ Department of Cosmetology of Fashion Design, Ching Kuo Institute of Management and Health \\ ${ }^{3}$ Dept. of Hospitality Management, Da Yeh University, Taiwan, R.O.C. \\ ${ }^{*}$ Corresponding author
}

\begin{abstract}
The study aims to explore sustainable and renewable energy application via a case study from green buildings to green sustainability. Therefore, first of all, the study reviews definitions of sustainable energy, renewable energy technologies, energy efficiency, smart-grid technology, green energy and green power, sustainable energy research includes solar, space-based solar power, wind. Secondly, the study discusses a case study from green buildings to green sustainability in TSMC, includes TSMC's response to climate change, GHG emission reduction, initiating TSMC carbon management, renewable energy application.
\end{abstract}

Keywords-sustainable and renewable energy; application; green buildings; green sustainability

\section{INTRODUCTION}

Sustainable energy is energy that is consumed at insignificant rates compared to its supply and with manageable collateral effects, especially environmental effects. Another common definition of sustainable energy is an energy system that serves the needs of the present without compromising the ability of future generations to meet their needs.[1] The organizing principle for sustainability is sustainable development, which includes the four interconnected domains: ecology, economics, politics and culture.[2] Sustainability science is the study of sustainable development and environmental science.[3] The sustainable energy apart from other renewable energy terminology such as alternative energy by focusing on the ability of an energy source to continue providing energy. Sustainable energy can produce some pollution of the environment, as long as it is not sufficient to prohibit heavy use of the source for an indefinite amount of time. Sustainable energy is also distinct from low-carbon energy, which is sustainable only in the sense that it does not add to the $\mathrm{CO} 2$ in the atmosphere. Green Energy is energy that can be extracted, generated, and/or consumed without any significant negative impact to the environment. The planet has a natural capability to recover which means pollution that does not go beyond that capability can still be termed green. Green power is a subset of renewable energy and represents those renewable energy resources and technologies that provide the highest environmental benefit.

The study aims to explore sustainable and renewable energy application via a case study from green buildings to green sustainability.

\section{LITERATURE REVIEW}

\section{A. Definitions of Sustainable Energy}

Energy efficiency and renewable energy are said to be the twin pillars of sustainable energy.[4][5] Some ways in which sustainable energy has been defined are: "Effectively, the provision of energy such that it meets the needs of the present without compromising the ability of future generations to meet their own needs. ...Sustainable Energy has two key components: renewable energy and energy efficiency." Renewable Energy and Efficiency Partnership (British)[1] "Dynamic harmony between equitable availability of energy-intensive goods and services to all people and the preservation of the earth for future generations." And, "The solution will lie in finding sustainable energy sources and more efficient means of converting and utilizing energy." Sustainable Energy by J. W. Tester, et al., from MIT Press. "Any energy generation, efficiency and conservation source where: Resources are available to enable massive scaling to become a significant portion of energy generation, long term, preferably 100 years.." - Invest, a green technology non-profit organization.[6] "Energy which is replenishable within a human lifetime and causes no long-term damage to the environment." - Jamaica Sustainable Development Network[7]

\section{B. Renewable Energy Technologies}

Renewable energy technologies are essential contributors to sustainable energy as they generally contribute to world energy security, reducing dependence on fossil fuel resources,[9] and providing opportunities for mitigating greenhouse gases.[9] The International Energy Agency states that: Conceptually, one can define three generations of renewables technologies, reaching back more than 100 years . First-generation technologies emerged from the industrial revolution at the end of the 19th century and include hydropower, biomass combustion and geothermal power and heat. Some of these technologies are still in widespread use. Second-generation technologies include solar heating and cooling, wind power, modern forms of bioenergy and solar photovoltaics. These are now entering markets as a result of research, development and demonstration (RD\&D) investments since the 1980s. The initial investment was prompted by energy security concerns linked to the oil crises (1973 and 1979) of the 1970s but the continuing appeal of these renewables is due, at least in part, to environmental benefits. Many of the technologies reflect significant 
advancements in materials. Third-generation technologies are still under development and include advanced biomass gasification, biorefinery technologies, concentrating solar thermal power, hot dry rock geothermal energy and ocean energy. Advances in nanotechnology may also play a major role. - International Energy Agency, RENEWABLES IN GLOBAL ENERGY SUPPLY, An IEA Fact Sheet[9] Firstand second-generation technologies have entered the markets, and third-generation technologies heavily depend on long term research and development commitments, where the public sector has a role to play.[9]

Regarding energy used by vehicles, a comprehensive 2008 cost-benefit analysis review was conducted of sustainable energy sources and usage combinations in the context of global warming and other dominating issues; it ranked wind power generation combined with battery electric vehicles (BEV) and hydrogen fuel cell vehicles (HFCVs) as the most efficient. Wind was followed by concentrated solar power (CSP), geothermal power, tidal power, photovoltaic, wave power, hydropower coal capture and storage (CCS), nuclear energy and biofuel energy sources. It states: "In sum, use of wind, CSP, geothermal, tidal, PV, wave, and hydro to provide electricity for BEVs and HFCVs and, by extension, electricity for the residential, industrial, and commercial sectors, will result in the most benefit among the options considered. The combination of these technologies should be advanced as a solution to global warming, air pollution, and energy security. Coal-CCS and nuclear offer less benefit thus represent an opportunity cost loss, and the biofuel options provide no certain benefit and the greatest negative impacts."[10]

\section{Energy Efficiency}

Moving towards energy sustainability will require changes not only in the way energy is supplied, but in the way it is used, and reducing the amount of energy required to deliver various goods or services is essential. Opportunities for improvement on the demand side of the energy equation are as rich and diverse as those on the supply side, and often offer significant economic benefits.[11]

Renewable energy and energy efficiency are sometimes said to be the "twin pillars" of sustainable energy policy. Both resources must be developed in order to stabilize and reduce carbon dioxide emissions. Efficiency slows down energy demand growth so that rising clean energy supplies can make deep cuts in fossil fuel use. If energy use grows too fast, renewable energy development will chase a receding target. A recent historical analysis has demonstrated that the rate of energy efficiency improvements has generally been outpaced by the rate of growth in energy demand, which is due to continuing economic and population growth. As a result, despite energy efficiency gains, total energy use and related carbon emissions have continued to increase. Thus, given the thermodynamic and practical limits of energy efficiency improvements, slowing the growth in energy demand is essential.[ 12] However, unless clean energy supplies come online rapidly, slowing demand growth will only begin to reduce total emissions; reducing the carbon content of energy sources is also needed. Any serious vision of a sustainable energy economy thus requires commitments to both renewables and efficiency.[13]
Renewable energy (and energy efficiency) are no longer niche sectors that are promoted only by governments and environmentalists. The increased levels of investment and the fact that much of the capital is coming from more conventional financial actors suggest that sustainable energy options are now becoming mainstream.[ 14]

\section{Smart-grid technology}

Smart grid refers to a class of technology people are using to bring utility electricity delivery systems into the 21st century, using computer-based remote control and automation.[ 15] These systems are made possible by two-way communication technology and computer processing that has been used for decades in other industries. They are beginning to be used on electricity networks, from the power plants and wind farms all the way to the consumers of electricity in homes and businesses. They offer many benefits to utilities and consumers-mostly seen in big improvements in energy efficiency on the electricity grid and in the energy users' homes and offices.[15]

\section{E. Green Energy and Green Power}

Green energy includes natural energetic processes that can be harnessed with little pollution. Green power is electricity generated from renewable energy sources.[ 16] Anaerobic digestion, geothermal power, wind power, small-scale hydropower, solar energy, biomass power, tidal power, wave power, and some forms of nuclear power (ones which are able to "burn" nuclear waste through a process known as nuclear transmutation, such as an Integral Fast Reactor, and therefore belong in the "Green Energy" category). Some definitions may also include power derived from the incineration of waste.

A more recent concept for improving our electrical grid is to beam microwaves from Earth-orbiting satellites or the moon to directly when and where there is demand. The power would be generated from solar energy captured on the lunar surface In this system, the receivers would be "broad, translucent tent-like structures that would receive microwaves and convert them to electricity". NASA said in 2000 that the technology was worth pursuing but it is still too soon to say if the technology will be cost-effective.[17] The World Wide Fund for Nature and several green electricity labelling organizations created the (now defunct) Eugene Green Energy Standard under which the national green electricity certification schemes could be accredited to ensure that the purchase of green energy leads to the provision of additional new green energy resources.[ 18]

The U.S. Environmental Protection Agency defines green power as electricity produced from solar, wind, geothermal, biogas, biomass and low-impact small hydroelectric sources. Customers often buy green power for avoided environmental impacts and its greenhouse gas reduction benefits.[8]

\section{F. Sustainable Energy Research}

There are numerous organizations within the academic, federal, and commercial sectors conducting large scale advanced research in the field of sustainable energy. This research spans several areas of focus across the sustainable energy spectrum. Most of the research is targeted at improving efficiency and increasing overall energy yields.[ 19] Multiple federally supported research organizations have focused on 
sustainable energy in recent years. Two of the most prominent of these labs are Sandia National Laboratories and the National Renewable Energy Laboratory (NREL), both of which are funded by the United States Department of Energy and supported by various corporate partners.[20] Sandia has a total budget of \$2.4 billion [21] while NREL has a budget of \$375 million.[ 22] Scientific production towards sustainable energy systems is rising exponentially, growing from about 500 English journal papers only about renewable energy in 1992 to almost 9,000 papers in 2011.[23]

1) Solar: The primary obstacle that is preventing the large scale implementation of solar powered energy generation is the inefficiency of current solar technology. Currently, photovoltaic (PV) panels only have the ability to convert around $16 \%$ of the sunlight that hits them into electricity.[24] At this rate, many experts believe that solar energy is not efficient enough to be economically sustainable given the cost to produce the panels themselves. Both Sandia National Laboratories and the National Renewable Energy Laboratory (NREL), have heavily funded solar research programs. The NREL solar program has a budget of around $\$ 75$ million [25] and develops research projects in the areas of photovoltaic (PV) technology, solar thermal energy, and solar radiation. [26] The budget for Sandia's solar division is unknown, however it accounts for a significant percentage of the laboratory's $\$ 2.4$ billion budget.[ 27] Several academic programs have focused on solar research in recent years. The Solar Energy Research Center (SERC) at University of North Carolina (UNC) has the sole purpose of developing cost effective solar technology. In 2008, researchers at Massachusetts Institute of Technology (MIT) developed a method to store solar energy by using it to produce hydrogen fuel from water.[28] Such research is targeted at addressing the obstacle that solar development faces of storing energy for use during nighttime hours when the sun is not shining. In February 2012, North Carolina-based Semprius Inc., a solar development company backed by German corporation Siemens, announced that they had developed the world's most efficient solar panel. The company claims that the prototype converts $33.9 \%$ of the sunlight that hits it to electricity, more than double the previous high-end conversion rate.[ 29] Major projects on artificial photosynthesis or solar fuels are also under way in many developed nations.[ 30]

2) Space-Based Solar Power: Space-Based Solar Power Satellites seek to overcome the problems of storage and provide civilization-scale power that is clean, constant, and global. Japan and China have active national programs aimed at commercial scale Space-Based Solar Power (SBSP), and both nation's hope to orbit demonstrations in the 2030s. The China Academy of Space Technology (CAST) won the 2015 International SunSat Design Competition with this video of their Multi-Rotary Joint design. Proponents of SBSP claim that Space-Based Solar Power would be clean, constant, and global, and could scale to meet all planetary energy demand.[50] A recent multi-agency industry proposal (echoing the 2008 Pentagon recommendation) won the SECDEF/SECSTATE/USAID Director D3 (Diplomacy, Development, Defense) Innovation Challenge [7] with the following pitch and vision video.[ 31] Northrop Grumman is funding CALTECH with $\$ 17.5$ million[32] for an ultra lightweight design.[8] Keith Henson recently posted a video of a "bootstrapping" approach.

3) Wind: The National Renewable Energy Laboratory projects that the levelized cost of wind power in the U.S. will decline about 25\% from 2012 to 2030.[ 33] Wind energy research dates back several decades to the 1970s when NASA developed an analytical model to predict wind turbine power generation during high winds.[ 34] Today, both Sandia National Laboratories and National Renewable Energy Laboratory have programs dedicated to wind research. Sandia's laboratory focuses on the advancement of materials, aerodynamics, and sensors.[ 35] The NREL wind projects are centered on improving wind plant power production, reducing their capital costs, and making wind energy more cost effective overall.[ 36] The Field Laboratory for Optimized Wind Energy (FLOWE) at Caltech was established to research renewable approaches to wind energy farming technology practices that have the potential to reduce the cost, size, and environmental impact of wind energy production.[ 37] The president of Sky Wind Power Corporation thinks that wind turbines will be able to produce electricity at a cent/kWh at an average which in comparison to coal-generated electricity is a fractional of the cost.[ 38]

Many of the largest operational onshore wind farms are located in the USA and China. The Gansu Wind Farm in China has over 5,000 MW installed with a goal of 20,000 MW by 2020. China has several other "wind power bases" of similar size. The Alta Wind Energy Center in California is the largest onshore wind farm outside of China, with a capacity of 1020 MW of power.[ 39] Europe leads in the use of wind power with almost $66 \mathrm{GW}$, about 66 percent of the total globally, with Denmark in the lead according to the countries installed per-capita capacity.[ 40] As of February 2012, the Walney Wind Farm in United Kingdom is the largest offshore wind farm in the world at 367 MW, followed by Thanet Wind Farm (300 MW), also in the UK. Wind power has expanded quickly, it's share of worldwide electricity usage at the end of 2014 was 3.1\%.[41]

\section{FROM GREEN BUILDINGS TO GREEN SUSTAINABILITY}

\section{A. TSMC's Response to Climate Change}

1) GHG Emission Reduction: According to [42], the semiconductor manufacturing process generally uses perfluorinated compounds (PFCs) such as CF4, C2F6, SF6, NF3, CHF3, C3F8, and C4F8, which are the major greenhouse gas emissions from the manufacturing process. After many years' efforts, TSMC has achieved its goal of reducing perfluorinated compound emissions to $10 \%$ below the average emission level of 1997 and 1999. This emission 
target remains fixed as TSMC continues to grow and construct new fabs, and has been a great challenge to them. TSMC continued to actively participate in the World Semiconductor Council's establishment of a global voluntary reduction goal for 2020. TSMC integrated past experience to develop best practices, which have been recommended by the Taiwan Semiconductor Industry Association and adopted by the World Semiconductor Council member companies as major measures to achieve these organizations' 2020 reduction goals.

2) Initiating TSMC Carbon Management: According to [42], Taiwan government amended "Greenhouse Gas Reduction and Management Act" and submitted its NDC (National Determined Contribution) to UNFCCC(United Nations Framework Convention on Climate Change) for COP21(21th Conference of the Parties, COP21) in 2015. The short-term and long term GHG reduction goals of Taiwan are in the articles. To keep working on energy saving and carbon emission reduction are not enough to face the challenge of carbon emission cap in the future. Following this trend, TSMC understands that the three issues of regulatory restrictions, carbon emission reduction, and external carbon credits me be reviewed and balance in total. The company also understands that the monetization of carbon credits will influence our sustainable development. Therefore, TSMC initiated a carbon management platform with a cross-function team to integrate regulatory information, emissions status monitoring and forecasts, and reduction activities to gain additional external carbon credits to ensure sufficiency for their emissions and future expansion under the annually tightening regulatory requirements. The platform is hosted by senior managers and takes both corporate operational risk control and environmental protection social responsibility into consideration. The cross-function team includes Corporate ESH, Operation and Financial organizations take their own responsibilities and collaborate closely to reach a tremendous integrated performance.

3) Renewable Energy Application : According to [42], the Taiwan government continues to establish sources of renewable energy, and TSMC is pleased to see this development. The Company purchased 100 million kWh of green power in 2015 to support the government's policy and became the biggest green power purchaser accounting for $64.1 \%$ of total green energy sold. TSMC fabs have also installed solar panel to generate renewable energy used in their facilities. As of 2015, their total solar panel capacity is $1,301 \mathrm{~kW}$, which has generated 5.37 trillion Joules and was equal to 1.49 million $\mathrm{kWh}$ in 2015. The above measures have reduced CO2 emission by about 50,000 tons in total. TSMC supported Taiwan government renewable energy development, and received a gift "Ginkgo tree sapling" from Mr. Deng, the Minister of the Ministry of Economic Affairs, R.O.C.

\section{B. From Green Buildings to Green Sustainability}

According to [43], TSMC began its Green Building Project in 2006, in which all new properties follow the standards of the USGBC Leadership in Energy and Environment Design (LEED) Rating System, and Taiwan Ecology, Energy Saving, Waste Reduction, and Health (EEWH) rating system. As of 2015, 18 TSMC buildings have been certified by the USGBC LEED standard; two have obtained Platinum ratings, and 16 have gained Gold ratings; 10 buildings have been certified with Taiwan EEWH Diamond ratings. TSMC initiated a green campus development policy at the end of 2010 to raise the efficiency of green buildings, optimize resource-sharing to reduce cost, eliminate unnecessary equipment and conserve resources, and to thrive alongside the natural environment through comprehensive site planning. TSMC plans to make Fab 12 in Hsinchu, Fab 15 in Taichung, and Fab 14 in Tainan into the company's three main green campuses. TSMC is committed to a green manufacturing policy and environment protection.

TSMC opens on-site touring of Green campus from 2007, continuing with Taiwan Green Building Council cooperation, F12P4 as a "green building education demonstration base", to hold routine green building visit. In addition, communicated with related industries, such as Formosa Plastics, AUO, ASE, Long chen Paper and Pegatron, etc., to discuss about the planning and execution of energy saving, water reclamation, waste reductions and green buildings. In 2015, guests included office of the President, the Executive Yuan, Ministry of Science and Technology, Architecture and Building Research Institute, Ministry of the Interior, Central Taiwan Science Park, Southern Taiwan Science Park and the Secretary of Zhejiang Jinhua Municipal Committee and other government units, National Cheng Kung University, National Central University, National Tsing Hua University and Beijing Tsing hua / Zhejiang University EMBA, Tung Hai University, Feng Chia University, Shanghai Nanyang Model High School related departments, Institute of Nuclear Energy Research, Atomic Energy Council, Society of Entrepreneurs \& Ecology, Apple computers and other representatives of private enterprises, totaling 1,344 people.to visit intelligent green campuses[43].

\section{CONCLUSIONS}

The study explores sustainable and renewable energy application via a case study from green buildings to green sustainability. First of all, the study reviews definitions of sustainable energy, renewable energy technologies, energy efficiency, smart-grid technology, green energy and green power, sustainable energy research includes solar, space-based solar power, wind.

Secondly, the study discusses a case study from green buildings to green sustainability in TSMC, includes TSMC's response to climate change, GHG emission reduction, initiating TSMC carbon management, renewable energy application.

TSMC initiated a carbon management platform with a cross-function team to integrate regulatory information, emissions status monitoring and forecasts, and reduction activities to gain additional external carbon credits to ensure 
sufficiency for their emissions and future expansion under the annually tightening regulatory requirements. As of 2015, 18 TSMC buildings have been certified by the USGBC LEED standard; two have obtained Platinum ratings, and 16 have gained Gold ratings; 10 buildings have been certified with Taiwan EEWH Diamond ratings. TSMC initiated a green campus development policy at the end of 2010 to raise the efficiency of green buildings, optimize resource-sharing to reduce cost, eliminate unnecessary equipment and conserve resources, and to thrive alongside the natural environment through comprehensive site planning.

\section{REFERENCES}

[1] Renewable Energy \& Efficiency Partnership (August 2004). "Glossary of terms in sustainable energy regulation" (PDF). Retrieved 2008-12-19.

[2] James, Paul; Magee, Liam; Scerri, Andy; Steger, Manfred B. (2015). Urban Sustainability in Theory and Practice:. London: Routledge.; Liam Magee; Andy Scerri; Paul James; Jaes A. Thom; Lin Padgham; Sarah Hickmott; Hepu Deng; Felicity Cahill (2013). "Reframing social sustainability reporting: Towards an engaged approach". Environment, Development and Sustainability. Springer.

[3] Lynn R. Kahle, Eda Gurel-Atay, Eds. Communicating Sustainability for the Green Economy. New York: M.E. Sharpe. ISBN 978-0-7656-3680-5 (2014)

[4] Obrecht, Matevz; Denac, Matjaz. "A sustainable energy policy for Slovenia: Considering the potential of renewables and investment costs". Journal of Renewable and Sustainable Energy. 5 (7). doi:10.1063/1.4811283. (2013)

[5] "The Twin Pillars of Sustainable Energy: Synergies between Energy Efficiency and Renewable Energy Technology and Policy" (PDF). Aceee.org. Retrieved 17 December 2014.

[6] "The Sustainable Energy Community :: invVest | invVEST Definition of Sustainable Energy". invVest. Retrieved 2010-07-08.

[7] Jamaica Sustainable Development Network. "Glossary of terms". Archived from the original on 2007-11-30. Retrieved 2008-04-19.

[8] "Green Power Defined | Green Power Partnership | US EPA". Epa.gov. 2006-06-28. Retrieved 2010-07-08.

[9] International Energy Agency. Renewables in global energy supply: An IEA facts sheet, OECD, 34 pages. Archived 12 October 2009 at the Wayback Machine. (2007)

[10] Jacobson, Mark Z.. "Review of solutions to global warming, air pollution, and energy security". Energy and Environmental Science. Royal Society of Chemistry. 2 (2): 148-173. doi:10.1039/b809990c. Retrieved 2008-12-21. (2009)

[11] InterAcademy Council. Lighting the way: Toward a sustainable energy future p. xvii. (2007)

[12] Huesemann, Michael H., and Joyce A. Huesemann. Technofix: Why Technology Won't Save Us or the Environment, Chapter 5, "In Search of Solutions: Efficiency Improvements", New Society Publishers, ISBN 978-0-86571-704-6. (2011)

[13] American Council for an Energy-Efficient Economy. The Twin Pillars of Sustainable Energy: Synergies between Energy Efficiency and Renewable Energy Technology and Policy Report E074. (2007)

[14] United Nations Environment Programme and New Energy Finance Ltd. (2007), p. 17.

[15] "Smart Grid | Department of Energy". Energy.gov. Retrieved 2013-08-21.

[16] Green power, fueleconomy.gov

[17] Britt, Robert Roy. "Could Space-Based Power Plants Prevent Blackouts?". Science. (15 August 2003)

[18] Eugene Green Energy Standard, Eugene Network. Retrieved 2007-06-07.

[19] S.C.E. Jupe; A. Michiorri; P.C. Taylor. "Increasing the energy yield of generation from new and sustainable energy sources". Sustainable energy. 14 (2): 37-62. (2007)
[20] "Defense-scale supercomputing comes to sustainable energy research". Sandia National Laboratories. Retrieved 2012-04-16.

[21] "Sandia National Laboratories" (PDF). Sandia National Laboratories. Retrieved 2012-04-16.

[22] Chakrabarty, Gargi, 16 April 2009. "Stimulus leaves NREL in cold" Denver Post

[23] Rizzi; et al.. "The production of scientific knowledge on renewable energies: Worldwide trends, dynamics and challenges and implications for management. In". Renewable Energy. 62: 657-671. doi:10.1016/j.renene.2013.08.030. (2014)

[24] "Improvement of efficiency for solar photovoltaic cell application" (PDF). BRAC University. Retrieved 2012-04-16.

[25] Chakrabarty, Gargi. "Stimulus leaves NREL in cold". Denver Post. (16 April 2009), Retrieved 2012-04-16.

[26] "Solar Research". NREL. Retrieved 2012-04-16.

[27] "Photovoltaics". Sandia. Retrieved 2012-04-16.

[28] "Major discovery' from MIT primed to unleash solar revolution". MIT News. Retrieved 2012-04-17.

[29] "Breakthrough: World's most efficient solar panel". SmartPlanet. Retrieved 2012-04-17.

[30] Artificial photosynthesis as a frontier technology for energy sustainability. Thomas Faunce, Stenbjorn Styring, Michael R. Wasielewski, Gary W. Brudvig, A. William Rutherford, Johannes Messinger, Adam F. Lee, Craig L. Hill, Huub deGroot, Marc Fontecave, Doug R. MacFarlane, Ben Hankamer, Daniel G. Nocera, David M. Tiede, Holger Dau, Warwick Hillier, Lianzhou Wang and Rose Amal. Energy Environ. Sci., 2013, Advance Article doi:10.1039/C3EE40534F

[31] "Space Solar Power Team Breaks Through at D3 Innovation Summit". www.nss.org. Retrieved 2016-05-22.

[32] "Northrop Grumman Corporation: News and Events - News Release". investor.northropgrumman.com. Retrieved 2016-05-22.

[33] E. Lantz, M. Hand, and R. Wiser. "The Past and Future Cost of Wind Energy," National Renewable Energy Laboratory conference paper no. 6A20-54526, page 4, (May 13-17, 2012)

[34] "Wind energy research reaps rewards". NASA. Retrieved 2012-04-17.

[35] "Wind energy". Sandia. Retrieved 2012-04-17.

[36] "Wind research". NREL. Retrieved 2012-04-17.

[37] "Wind resource evaluation at the Caltech Field Laboratory for Optimized Wind Energy (FLOWE)" (PDF). Caltech. Retrieved 2012-04-17.

[38] Smil, Vaclav. "Electricity From Wind." Energy Myths and Realities: Bringing Science to the Energy Policy Debate. Washington, D.C.: AEI, 2010. 120-21. Print.

[39] [3]

[40] Smil, Vaclav. "Electricity from Wind." Energy Myths and Realities: Bringing Science to the Energy Policy Debate. Washington, D.C.: AEI, 2010. 115-30. Print.

[41] http://www.ren21.net/wp-content/uploads/2015/07/REN12-GSR2015_O nlinebook_low1.pdf pg31

[42] TSMC, TSMC's Response to Climate Change, http://www.tsmc.com/english/csr/climate_change.htm(2016a)

[43] TSMC, From Green Buildings to Green Sustainability, http://www.tsmc.com/english/csr/green_building.htm(2016b) 